\title{
MOBILE OPTOELECTRONIC MEASUREMENT OF A CONTACT NET CONSTRUCTION IN RAILWAYS
}

\author{
Rav.M.Galiulin, Rish.M.Galiulin, J.M.Bakirov, V.V.Bydanov \\ D.R.Bogdanov, D.V.Naumov \\ Department of Informatics, Ufa State Aviation Technical University \\ (USATU), \\ Ufa, 450000, Republic Bashkortostan, Russian Federation \\ Phone/Fax (007)3472-236542 E-Mail: head@optel.ugatu.ac.ru
}

\begin{abstract}
Abslract: The technical characteristics, advantages and applications of an automated optoelectronic measuring system designed in "Optel" company, Ufa State Aviation Technical University are presented in this paper. The mobil measuring system applied for inspection contact net constructions in electrified railways. It is a non-contact optoelectronic computer-aided system, allowing rapid measurements of unary and double contact wire parameters: wear, height, zigzag and quality of slide surface.
\end{abstract}

Keywords: optoelectronic, measurement, railways, contact net, construction, wire, wear, height, zigzag, quality of slide surface, software.

\section{INTRODUCTION}

Existing hand-operated and visual monitoring of wear of a contact wire (CW), which is used in contact network in electrified railways do not answer the modern requirements. $\mathrm{CW}$ under high voltages is dangerous for personnel. Therefore, the decision of a problem of automation of contact network parameters measurement is rather urgent.

Laser measuring apparatus of contact wire wear is known [2]. The principle of the laser apparatus consists in the following: the laser beam scans the width of the contact wire using a rotary mirror, and the reflected light from it is detected by a photoelectric element.

Known device has series of disadvantages:

- high power of laser beam (more than 350

$\mathrm{mW}$ ) is danger for personnel.

- large laser equipment dimensions and high cost of measuring system with optic and mechanic elements, which provide laser scanning

( $2400 \times 1600 \times 1470$ and $2500 \times 1000 \times 400 \mathrm{MM}$ ).

- the wear, height and zigzag can not be measured simultaneously.

$\mathrm{CW}$ wear video monitoring known as "shape from shading" method [1] is inconvenient, because it is impossible to measure:

- CW size under a fastening unit, elements of suspension and sites directly under plugs, where $\mathrm{CW}$ can be frequently broken;

- parameters of double wire;
- CW wear, zigzag and height simultaneously.

In the case described above one can measure only maximum size of the whole construction, but only wire size is needed.

\section{MEASURING PRINCIPLES AND METHODS}

The most acceptable methods of the noncontact CW control are the optoelectronic measuring methods and facilities, which are the most efficient. They are non-contact and distinguished by high precision, speed of response and universality $[3,4]$.

$\mathrm{CW}$ is radiated by special light beam and the image is projected on a CCD or photo-diode CMOS array. It provides non-contacts and high productivity when measuring system is moving fast.

The generated signals are filtered to eliminate noise. They are converted by ADC and digitized (Fig.1) and then processed by a computer, which uses the software. Software also generates other parameters and documents.

The $\mathrm{CW}$ parameters are determined from formula:

$$
\begin{aligned}
& \mathrm{L}=0,5 *\left(\mathrm{~L}_{1}+\mathrm{L}_{2}\right) *(\mathrm{H}-\mathrm{F}) / \mathrm{F} \\
& \mathrm{Z}=\mathrm{X}_{1} * \mathrm{~B} /\left(\mathrm{X}_{1}+\mathrm{X}_{2}\right)-0,5 \times \mathrm{B}, \\
& \mathrm{H}=\mathrm{F}+\mathrm{F} * \mathrm{~B} /\left(\mathrm{X}_{1}+\mathrm{X}_{2}\right),
\end{aligned}
$$


where $L$ - friction platform ( size of a friction platform determine wear),

$\mathrm{L}_{1}, \mathrm{~L}_{2}$ - size of projections of a light beam

reflected by a contact wire, on the array,

$\mathrm{H}-\mathrm{CW}$ height,

F - focal length of optical systems,

$\mathrm{Z}$ - CW zigzag,

$\mathrm{B}$ - base line,

$X_{1}$ and $X_{2}$ - distance between extreme points of a contact wire projection on an array and optical axes of optical systems.

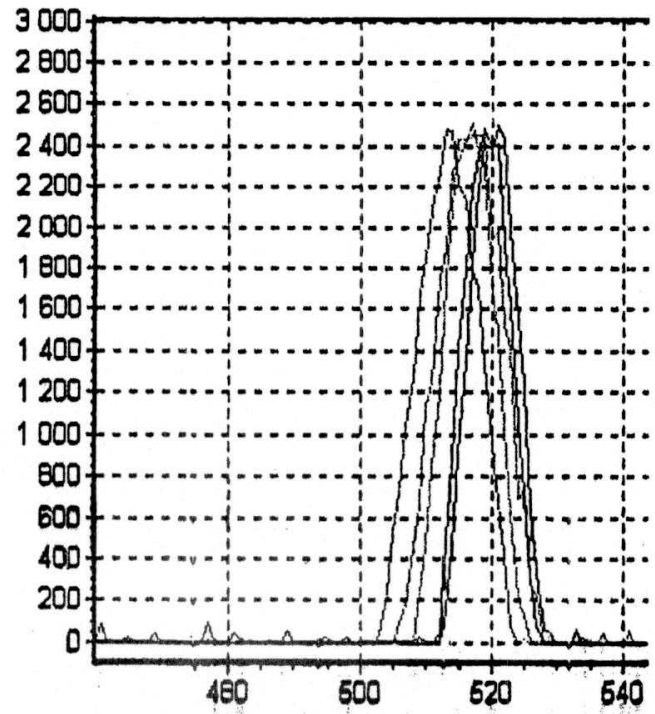

Fig. 1. Example of a digital ADC signals from $\mathrm{CW}$ with difference wear

Some variants of high-speed optoelectronic methods of measurements are offered and are realized. Measuring system is realized and tested onboard in real conditions.

New digital system is intended for automated simultaneous measurements of $\mathrm{CW}$ wear, zigzag and height realized for mobile research laboratory, locomotive and tram.

\section{THE SYSTEM ARCHITECTURE}

The system consists of automated working place controller with optoelectronic heads, light sources, and electronic unit based on the computer PENTIUM with the specialized new software.

The measurement data are transmitted from the optoelectronic heads to the electronic control module where noise is removed and an analog to digital conversion is done produce suitable signals for the computer.

This software realizes control of automated non-contact measurements, processing, and display in digital and graphic forms, saving of measuring results in memory. The original software allows working with a system without special preparation and contains all the necessary instruction information with output of results in a form required in railways. The automated control single or double $\mathrm{CW}$ is realized.

\section{FIELD TESTS IN REAL CONDITIONS}

The preliminary tests of system in sunshine day and night with speed of a movement up to 80 kilometers per hours are carried out. The measurements were carried out on electric inspection car-laboratory, motorized tower measuring car and tram-laboratory.

\section{TECHNIQUE, CONDITIONS OF REALIZATION}

The small dimensions of new system allow establishing it, excepting as on the electric inspection car-laboratory, locomotive, and tram. The significant work on constructive binding of system to self-propelled vehicle is spent. Constructive alterations vehicle and his pantograph it is not required.

The results of measurements simultaneously of $\mathrm{CW}$ wear, zigzag and height with a movement are displaying on the screen in the digital and graphic forms and saving in hard disk drive of the computer. The following functions are realized:

- Viewing of results of measurements of wear, zigzag, and heights $\mathrm{CW}$ with an automatic mark anker sites during measurements in digital and graphic forms,

- Viewing of any parameter already of measured site of a way in a kind, convenient for the user, - Distribution of results and protocols on machine carriers of the information and on a paper through the color printer.

\section{TECHNICAL CHARACTERISTICS} in table 1.

The characteristics of system are given

Table 1. Technical characteristics

\begin{tabular}{|l|l|l|}
\hline № & Characteristic & $\begin{array}{l}\text { Measureme } \\
\mathrm{nt}\end{array}$ \\
\hline 1 & $\mathrm{CW}$ types & $\begin{array}{l}\text { unary or } \\
\text { double }\end{array}$ \\
\hline 2 & $\begin{array}{l}\text { Range of measurement } \\
\text { of CW wear surface, } \mathrm{mm}\end{array}$ & from 2 \\
\hline 3 & $\begin{array}{l}\text { Resolution on CW section, } \\
\mathrm{mm}^{2} \text { (wear CW, mm ) }\end{array}$ & $0,05(0,06)$ \\
\hline 4 & $\begin{array}{l}\text { Measuring range of } \\
\text { a CW zigzag, mm }\end{array}$ & $\begin{array}{l}\text { from }-600 \\
\text { up to } \\
+600\end{array}$ \\
\hline
\end{tabular}




\begin{tabular}{|c|l|l|}
\hline 5 & $\begin{array}{l}\text { Measuring range of } \\
\text { distance between left and } \\
\text { right CW in a zigzag, mm }\end{array}$ & $\begin{array}{l}\text { from } 10 \\
\text { up to } \\
1100\end{array}$ \\
\hline 6 & $\begin{array}{l}\text { Resolution on a } \\
\mathrm{CW} \text { zigzag, mm }\end{array}$ & 1 \\
\hline 7 & $\begin{array}{l}\text { Measuring range of CW } \\
\text { heights suspension, } \\
\text { separately left and right } \\
\mathrm{CW} \text { (changeable), mm }\end{array}$ & $\begin{array}{l}\text { from } \\
5500 \\
\text { up to } \\
6800\end{array}$ \\
\hline $\mathbf{8}$ & $\begin{array}{l}\text { Resolution on CW height, } \\
\text { mm }\end{array}$ & 1 \\
\hline 9 & Vehicle speed, km an hour & $\begin{array}{l}\text { From } 0 \text { up } \\
\text { to } 300\end{array}$ \\
\hline
\end{tabular}

\section{MEASURING RESULTS}

Fig. 2 shows a measuring results of double contact wire on "Kasaiak-Ulutelak" distance, near Ufa, Bashkortostan, RF.
There are patterns of real data in graphic measuring protocol diagram of one railway distance with separate electric power supply (ankers). Its length is about $2000 \mathrm{~m}$, and it includes 18 supports.

From Fig. 2 one can see that the first half of this site has sufficiently increased wear. There are extremals ("red points") on the first graph, where wear is more than $35 \mathrm{~mm}^{2}$. It means that the breaks can occur in these places and an old $\mathrm{CW}$ must be changed with a new $\mathrm{CW}$ as soon as possible.

You can see CW zigzag on the second graph. There was a railway turn in the first half of site of railway distance, which is visible on the zigzag curves at the graph. The zigzags are within the tolerance limits, except zigzag near support \# 259 , where it is $542 \mathrm{~mm}$.

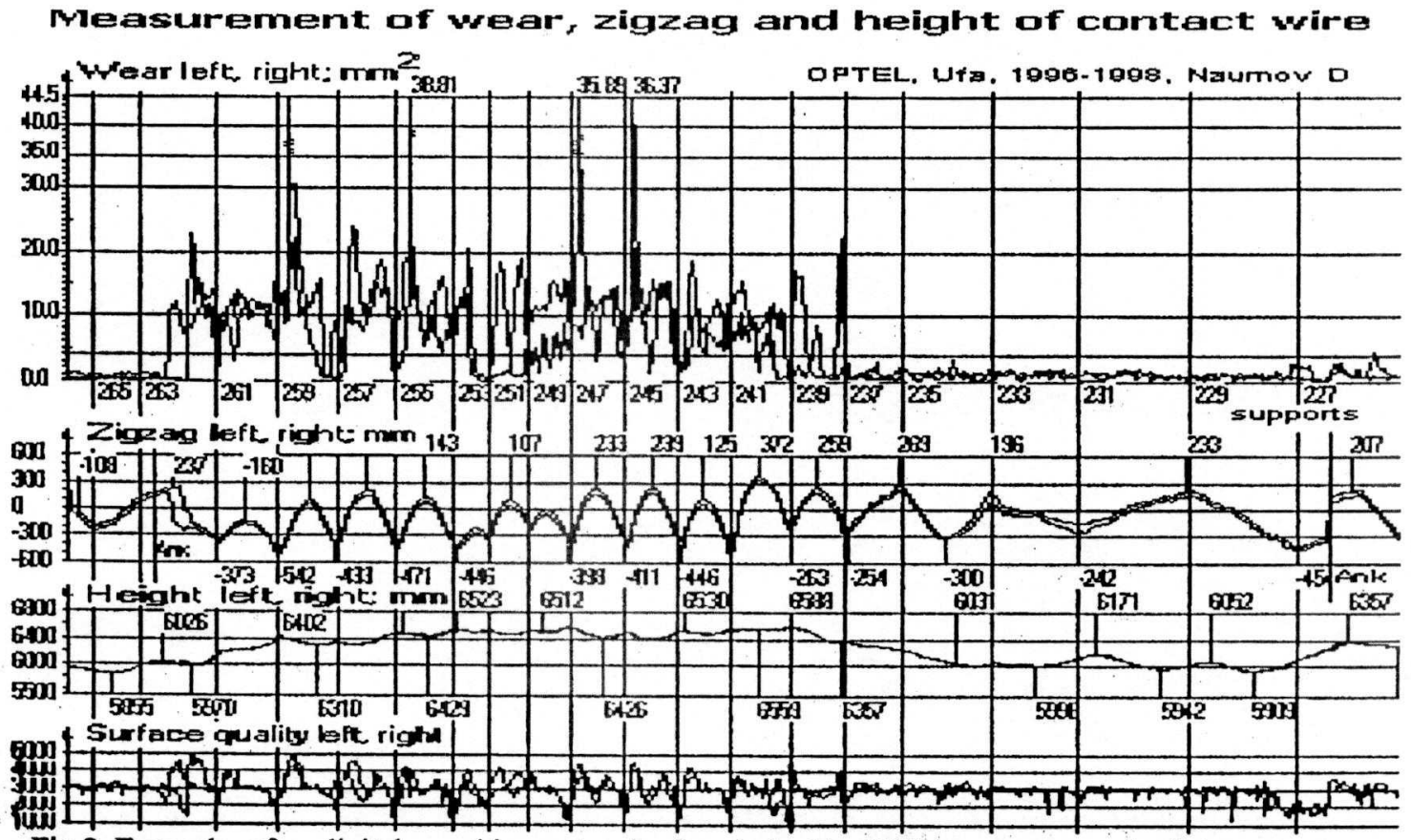

Fig.2. Example of a digital graphic protocol of real double $\mathrm{CW}$ measurements ( railways contact net construction): wear, zigzag, height and slide surface quality

The height of the first half of $\mathrm{CW}$ suspension (on the average about $6430 \mathrm{~mm}$ ) is more than heights of the second site (about 6000 $\mathrm{mm})$. This variation is tolerant.

The wire surface quality of the first site is worse then surface quality of second part of graph.

The measuring time by new computer system of the above-stated site is about 2 minutes. For comparison, the measuring time of handoperated monitoring of this railway distant is about $2-3$ days.
The comparisons of the measuring results of wear, obtained by the new digital system, with data, obtained by using the existing contact measurement methods, and were carried out. Comparisons of measurements of a zigzag and height $\mathrm{CW}$ with the data received simultaneously on recorder of the electric inspection car-laboratory were also carried out with its transportation together with motorized tower measuring car 'ARV-1'. A good concurrence of results was obtained. 


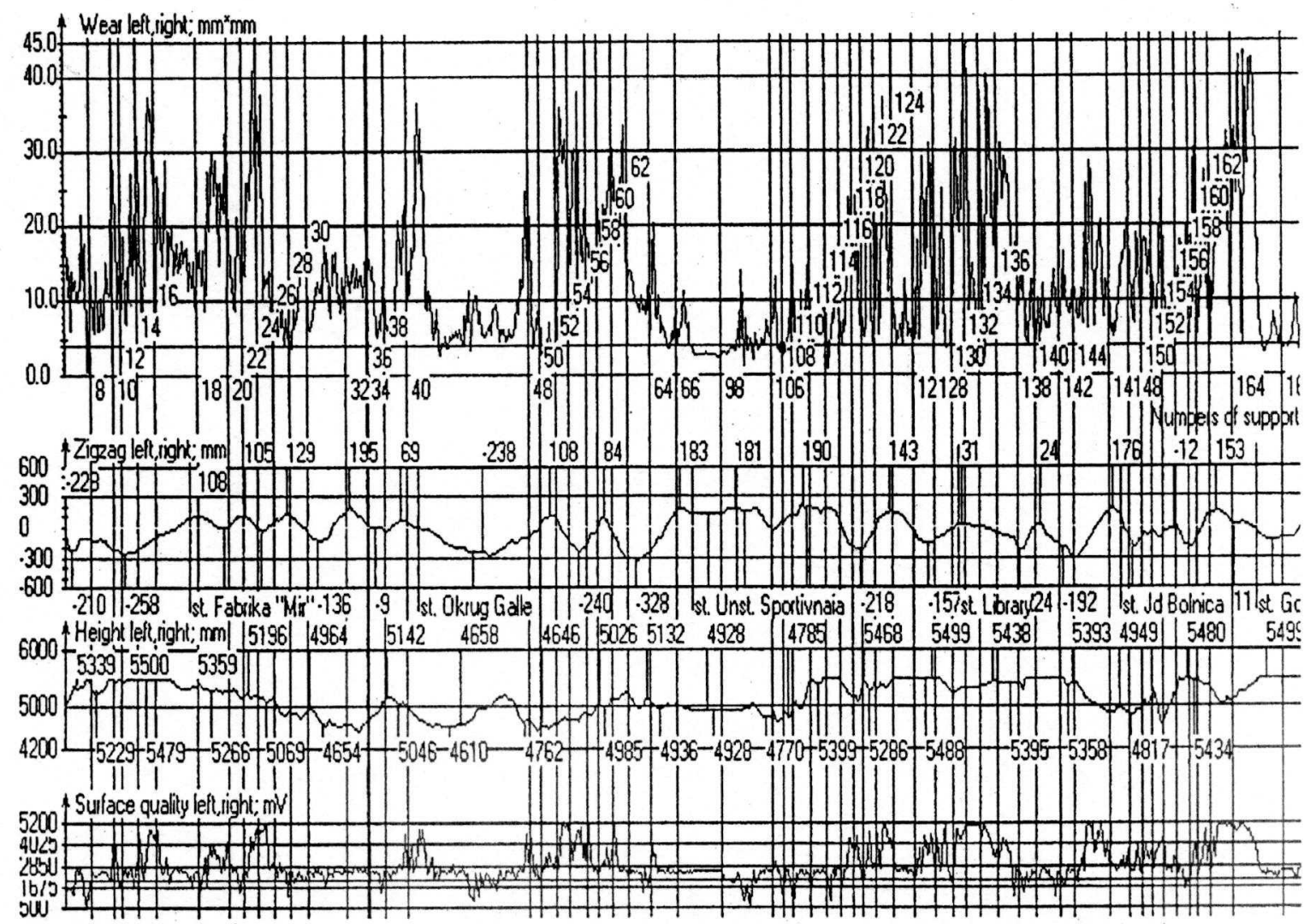

Fig.3. Example of a digital graphic protocol of real unary $\mathrm{CW}$ measurements ( tram contact net construction ): wear, zigzag, height and slide surface quality

"OPTEL" systems can be used also for a measurement of $\mathrm{CW}$ wear, height, zigzag and quality of surface of tram track. Fig. 3 shows a measuring results of unary contact wire of tram track, Ufa, Bashkortostan, RF.

Owing to measurements of a large set of $\mathrm{CW}$ points (up to 10000 between supports of $\mathrm{CW}$ ) the casual making error of measurements is reduced up to $30-100$ time in comparison with single-point hand - operating $\mathrm{CW}$ monitoring. It should be especially noted, that the offered method permits to measure wear along the whole $\mathrm{CW}$, including sites of concentrated weightdirectly under plugs, and reveal sites with critical and lateral wears, where breakage can frequently take place.

High accuracy and productivity of the "OPTEL" system permit to automate process of CW measurements and to provide fast round-theclock monitoring. It can exclude influence of the human factors of the hand-operated measurements and processing of results.

The time of $\mathrm{CW}$ measurements is reduced in $600-10000$ times. Many of the operators, working in a dangerous zone are released. The serviceability and high characteristics of the system are confirmed by carried out winter and summer tests ( from $-35^{\circ} \mathrm{C} \cdot$ to $+30^{\circ} \mathrm{C}$ ) on railway in real conditions [5].

All the factors mentioned above permit to reduce considerably heavy work and costs on realization of the control of a contact network, to increase safety of trains' traffic.

\section{CONCLUSIONS}

1. For the first time in a CIS the unique computer-aided system for automated non-contact simultaneous measurements of wear, zigzag and heights of a real contact wire corresponding to all modern requirements is created. Quality of surface of the CW slide surface is also supervised.

2. High accuracy and productivity of new system allow automating measurements. It gets contact wire parameters and ensures the fast round-the-clock and all-the-year-round control. The influence of the subjective factors of the hand-operated control is excluded.

3. The software of system allows to analyze $\mathrm{CW}$ wear and to predict residual service life of the wire with a conclusion of results as the standard target protocols. 
4. The high characteristics of new noncontact computer-aided system are confirmed by results of the winter and summer tests (from $-35^{\circ} \mathrm{C}$ to $+30^{\circ} \mathrm{C}$ ), carried out in real conditions.

\section{REFERENCES}

[1] P.Pohl. "Der Hagener VideoMesstriebwagen.", Der Eisenbahningenieur, N 7 pp. 32- 35, (47). 1996.

[2] T.Shimada, T. Kohida, Y. Satoh. "Development of a Solid Laser Measuring Apparatus of Contact Wire Wear". Quarterly Report of RTRI. Vol.38. N1 (March). pp. 19-24. 1997.

[3] Rav. M. Galiulin, Rish. M. Galiulin, A.S. Krasheninnikov, K.F. Tagirova. "Optoelectronic Measuring Systems and their applications." Proceedings of Asia-Pasific Conference on Control \& Measurement, Transactions of Nanjing University of Aeronautics \& Astronautics, vol. 10. N1, p. 275. Kunming, China. 1993.
[4] Rav.M. Galiulin, Rish.M. Galiulin, J.M. Bakirov and others, "Computer-Aided Laser Optoelectronic OPTEL 3-D Measurement Systems of Complex-Shaped Object Geometry." Editors: V.Panchenko, V.Golubev, Proceedings SPIE 2713, Bellingham, USA, Vol. 2713 pp. 393-399, 1996

[5] Galiulin Rav.M., Galiulin Rish.M., Bydanov V.V., Bakirov Zh.M., Naumov D.V. "Digital measurements of wear, zigzag and height of a contact wire in railways." Proceedings of 10th International Symposium on Development in Digital Measuring Instrumentation (ISDDMI'98) and 3th Workshop on ADC Modelling and Testing, IMEKO TC-4 Technical Commitee on Measurement of Electrical Quantities, Naples, University of Naples Federico II, Italy. Vol. 3. pp. 909-911. 1998. 